\title{
Intrusão em dentes permanentes: relato de caso
}

\author{
Intrusion in permanent teeth: case report
}

Intrusión en dientes permanentes: informe de caso

Amanda Letícia dos Santos Freitas ${ }^{1}$, Júlia Lorena Cavalcante Calheiros ${ }^{1}$, Íris Régia Ventura Barros ${ }^{1}$, Ana Luiza Cabral Mendes Santos ${ }^{1}$, Monaly de Oliveira Lima ${ }^{1}$, Irenilda Pereira Lins Lemos ${ }^{1}$, Anderson de Oliveira Rocha ${ }^{1}$, Fernanda Freitas Lins ${ }^{1 *}$.

\section{RESUMO}

Objetivo: Descrever uma conduta adequada para o traumatismo dentário do tipo luxação intrusiva partindo do seu diagnóstico à conduta inicial, tratamento e proservação. Detalhamento do caso: No presente relato de caso, o paciente apresentou traumatismo dentário, com comprometimento de três elementos dentais, onde os dentes 11 e 21 apresentaram intrusão severa com fratura de esmalte e dentina associada, com posterior necrose pulpar e reabsorção inflamatória externa; o dente 12 apresentou fratura coronorradicular, e pela extensão da fratura, foi optado posteriormente pela extração coronária e sepultamento da raiz.Os dentes 11 e 21 foram reposicionados cirurgicamente, tratados endodonticamente e proservados durante 12 meses. Considerações Finais: O manejo dos dentes intruídos, principalmente com rizogênese completa, ou seja, dentes permanentes maduros, possuem um prognóstico de caráter duvidoso. Sendo assim, é necessária uma avaliação clinico-radiográfica criteriosa, com uma anamnese e exames complementares minuciosos a fim de oferecer o melhor tipo de tratamento para cada caso de forma individual, evitando sequelas indesejáveis e obtendo um prognóstico satisfatório.

Palavras-chave: Diagnóstico, Endodontia, Reabsorção da raiz, Dentição permanente.

\section{ABSTRACT}

Objective: Describe an appropriate management for dental trauma of the type intrusive dislocation, starting from its diagnosis to the initial management, treatment and preservation. Case Detail: In the present case report, the patient presented severe intrusion dental trauma involving three dental elements, where teeth 11 and 21 presented severe intrusion with enamel fracture and dentin associated, with subsequent pulp necrosis and external inflammatory resorption; tooth 12 had a coronoradicular fracture, and due to the extent of the fracture, it was later decided to have coronary extraction and burial of the root. Teeth 11 and 21 were surgically repositioned, treated endodontically and maintained for 12 months. Final Considerations: The management of intruded teeth, especially when permanent with complete rhizogenesis, has a doubtful prognosis, and a careful clinical and radiographic evaluation are necessary, with an anamnesis and thorough complementary exams, in order to offer the best type of treatment for each case individually and avoid undesirable sequels and obtaining a satisfactory prognosis.

Keywords: Diagnosis, Endodontics, Root resorption, Permanent dentition.

\section{RESUMEN}

Objetivo: Describir un manejo apropiado para el trauma dental del tipo dislocación intrusiva, comenzando desde su diagnóstico hasta el manejo inicial, tratamiento y conservación. Detalles del caso: en el presente informe de caso, el paciente presentó trauma dental, del tipo de intrusión grave, con la participación de tres

${ }^{1}$ Centro Universitário CESMAC (CESMAC), Maceió-AL. *E-mail: fernandasu@hotmail.com 
elementos dentales, donde los dientes 11 y 21 presentaron intrusión severa con fractura de esmalte y dentina asociada, con necrosis pulpar posterior resorción inflamatoria externa; el diente 12 tenía una fractura coronoradicular y, debido a la extensión de la fractura, más tarde se decidió realizar una extracción coronaria y enterrar la raíz. Los dientes 11 y 21 fueron reubicados quirúrgicamente, tratados endodónticamente y mantenidos durante 12 meses. Consideraciones finales: el manejo de dientes intrusivos, especialmente aquellos con rizogénesis completa, constituye un pronóstico dudoso; por lo tanto, es necesaria una evaluación clínica y radiográfica cuidadosa, con anamnesis y exámenes complementarios detallados, para ofrecer el mejor tipo de tratamiento para cada caso individual, evitando secuelas indeseables y obteniendo un pronóstico satisfactorio.

Palabras clave: Diagnóstico, Endodoncia, Reabsorción radicular, Dentición permanente.

\section{INTRODUÇÃO}

Lesões traumáticas dentais são resultado de uma transmissão aguda de energia ao dente - vide impacto - e suas estruturas adjacentes que comumente estão interligadas com fraturas, deslocamentos dentais, rompimento e/ou esmagamento das estruturas de suporte (GRANVILLE-GARCIA AF, et al., 2008).

Pode acontecer de forma acidental ou proposital, com etiologia mais habitual de quedas, violência ou acidentes automobilísticos, podendo ainda estar relacionada a fatores anatômicos suscetíveis como sobressaliência e sobremordida (SANTOS RS, et al., 2018).

De acordo com o exposto na literatura, traumas dentais que envolvem o deslocamento do dente de sua posição inicial são subdivididos em intrusão, extrusão e luxação lateral e classificados em consonância com a direção do deslocamento (AMARAL RPR, 2017; ANDREASEN JO, et al., 2006).

Nesse sentido, são considerados traumas dentários de intrusão todos os impactos axiais que gerem danos ao tecido pulpar e suas estruturas adjacentes como o periodonto, raiz e osso alveolar, sendo a lesão que mais acomete os tecidos de suporte (ANDREASEN JO, et al., 2006; LEMOS IGS, 2018).

Em dentes permanentes, a intrusão é uma das lesões mais graves de luxação. Compõe aproximadamente $1,9 \%$ das lesões traumáticas que envolvem o grupo dentário e comumente afetam dois ou mais dentes (DHARMANI U, et al., 2014).

Geralmente, a raiz dentária é projetada para dentro do alvéolo levando ao esmagamento do ligamento periodontal e do feixe vásculo-nervoso da polpa.

Como resultado, as sequelas se estendem em necrose do tecido pulpar, fratura do osso alveolar, reabsorção radicular e possível risco de perda do elemento dental (LEMOS IGS, 2018; SANABE ME, et al., 2009).

Em rotina, o diagnóstico é realizado com auxílio clínico e radiográfico, onde o trauma é medido em graus de intrusão avaliados de acordo com a altura incisal dos dentes afetados e dos dentes adjacentes nãoafetados, ou a distância da junção amelo-cementária dos mesmos.

De acordo com o grau de deslocamento clínico, os dentes intrusos podem ser classificados em 3 categorias: intrusão leve $(<3 \mathrm{~mm})$, intrusão moderada $(3-6 \mathrm{~mm})$ e intrusão severa $(>6 \mathrm{~mm})$ (SRIVASTAVA VPA, et al., 2014).

De modo geral, o tratamento depende do grau de intrusão, que pode ser classificado ainda em Classe I, quando tiver dentes com mais de $50 \%$ da coroa visível, Classe II quando está menos de $50 \%$ da coroa visível e Classe III para dentes sem coroa visível (COSTA V, et al, 2016).

Cabe ao cirurgião-dentista avaliar o caso e analisar os dados do acompanhamento periódico. No entanto, à medida em que o grau de intrusão se aprofunda, também se considera uma intervenção menos conservadora: o reposicionamento cirúrgico (LEMOS IGS, 2018); (SANABE ME, et al., 2009).

As complicações decorrentes da intrusão dentária mais comuns na dentição permanente são a necrose pulpar devido à ruptura do feixe neurovascular ou contaminação bacteriana por exposição e a reabsorção 
radicular externa (LEMOS IGS, 2018). Pode ocorrer ainda, porém com menor frequência, recessão gengival e obliteração pulpar (RAI P, et al., 2016).

Cabe ao profissional de saúde realizar uma anamnese criteriosa e colher todas as informações clínicoradiográficas com destreza a fim de proporcionar um correto diagnóstico e oferecer melhores opções de tratamento de acordo com as medidas terapêuticas disponíveis.

Diante disso, o estudo de caso clínico objetiva discutir acerca das características clínicas e radiográficas da intrusão, seu diagnóstico e possibilidades de tratamento, visando auxiliar os profissionais da área de saúde a oferecer uma melhor opção de tratamento em cada caso, contribuindo na melhora do prognóstico e na qualidade de vida do indivíduo.

\section{RELATO DE CASO}

Paciente do sexo masculino, 13 anos de idade, compareceu a clínica de infantildo centro universitario cesmac, com a seguinte queixa principal "meus dentes entraram". No exame clínico constatou-se comprometimento de 3 elementos dentais, foi observado a intrusão dos elementos 21 e 11 apresentando fratura de esmalte e dentina.

No dente 12 observou-se uma fratura coronorradicular, devido a uma queda de propria altura, onde o mesmo colidiu nos trilhos de trem.

O mesmo relatou estar fazendo uso dos seguintes medicamentos: Amoxicilina $500 \mathrm{mg}$ de $8 \mathrm{em} 8$ horas pelo período de 7 dias e Neomicina $10 \mathrm{~g}$ de $24 \mathrm{em} 24$ horas pelo período de 3 dias, onde foram prescritos no atendimento emergencial do hospital geral do estado horas após o trauma (Figura 1).

Figura 1 - A: Aspecto clínico inicial demonstrando a intrusão severa dos elementos 11 e 21. B: Radiografia inicial obseva-se o comprometimento dos elementos 11 e 21 na intrusão e a fratura coronorradicular do elemento 12.

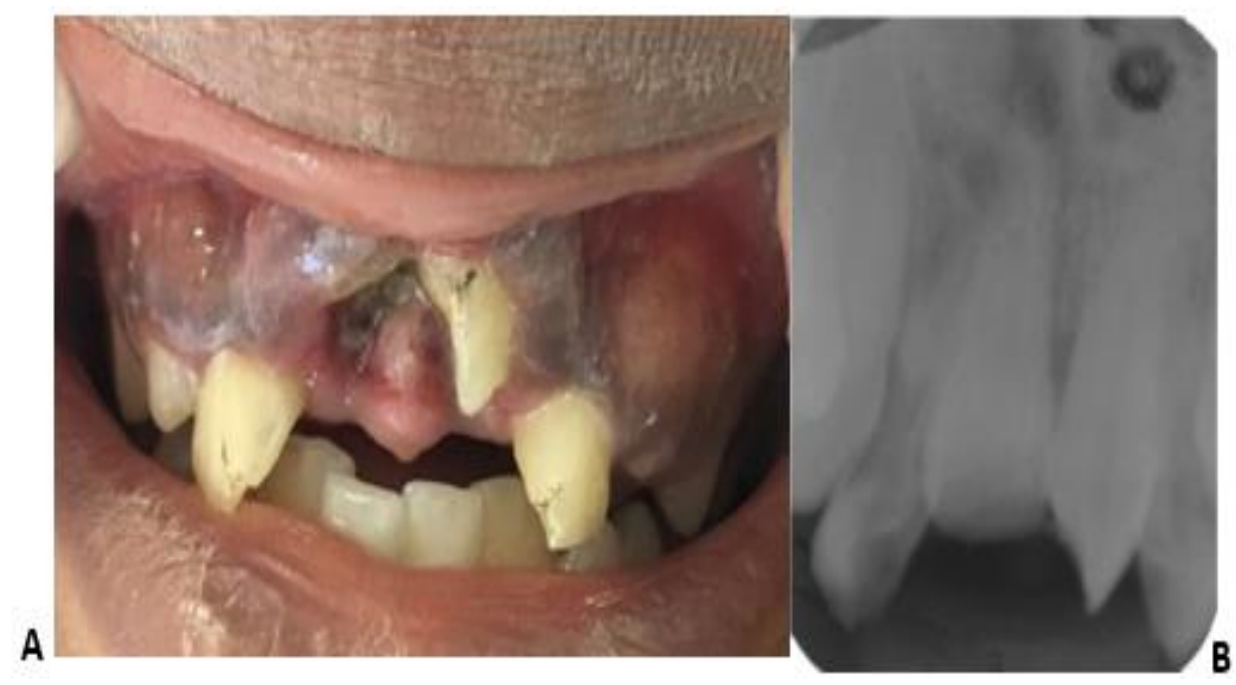

Fonte: Freitas ALS, et al., 2019.

No atendimento de urgência realizado na clínica de odontologia do Centro Universitário CESMAC, 2 dias após o trauma,foram realizadas radiografias periapicais dos elementos comprometidos, seguido da anestesia com lidocaína 2\% e epinefrina 1:100.000.

Inicialmente, foi proposto reposicionar os elementos dentários 11 e 21 com o fórceps 150, porém não obtendo sucesso devido a falta de apoio ao dente, para a utilização do mesmo, então foi proposto operar com o porta-agulha (Figura 2 A, B e C).

Logo após, confeccionou-se uma contenção semi-rígida com amarrilha e resina composta em seis dentes (Figura 2 D), sendo realizado o encaminhamento para a extensão de trauma do CESMAC. 
Figura 2 - A: Reposicionamento dos elementos 11 e 21 utilizando o porta-agulha. B: Elementos 12,11 e 21 reposicionados. C: Elementos dentais 11 e 21 reposicionados. D: Contenção semi-rígida com amarrilha e resina composta nos elementos 13, 12, 11, 21, 22 e 23 .

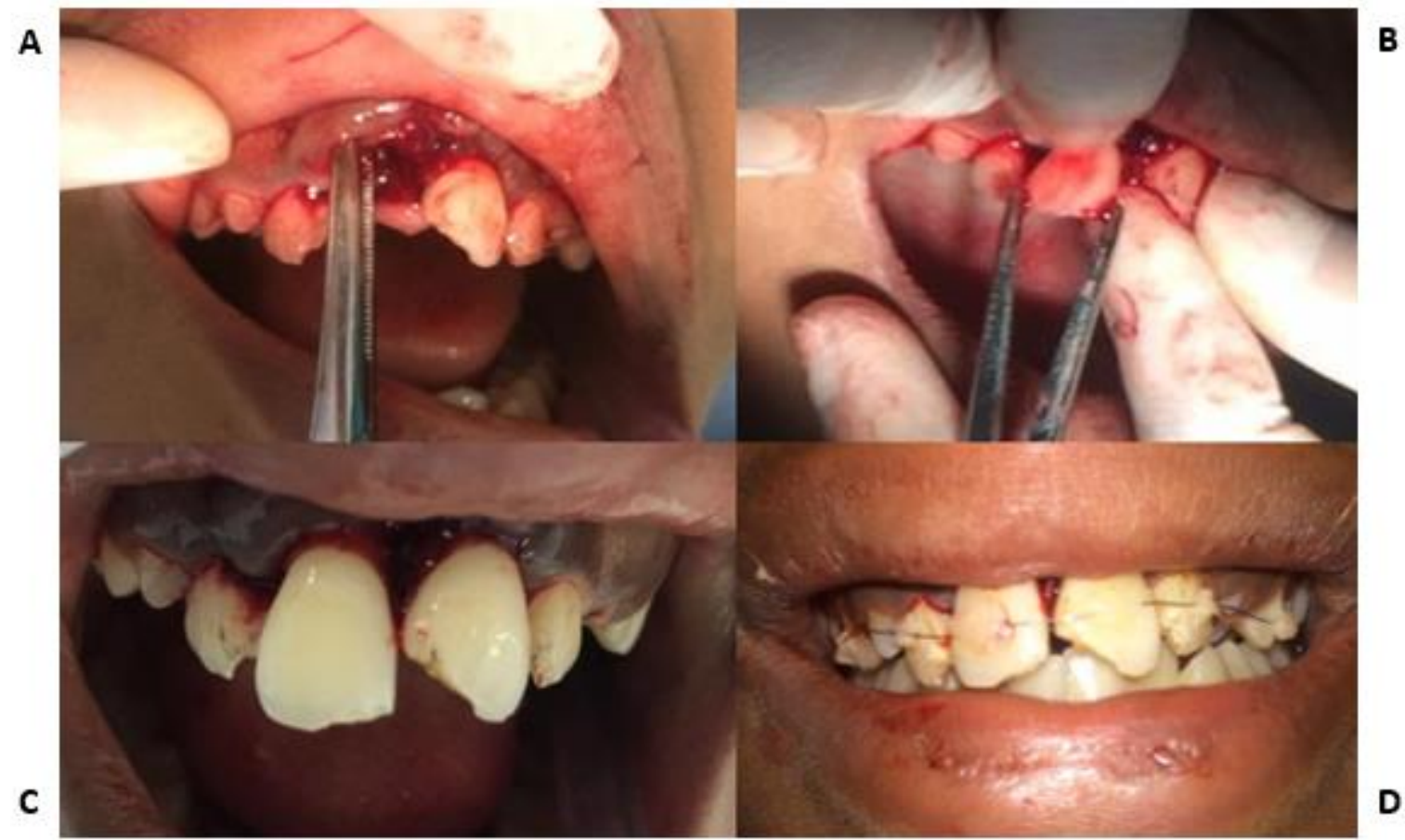

Fonte: Freitas ALS, et al., 2019.

Na segunda sessão, após 8 dias, efetuada na extensão de trauma, optou-se por realizarnovas radiografias dos dentes afetados (Figura 3 A), a contenção anterior apresentou-se defeituosa, devido ao alto sangramento durante o reposicionamento, que foi realizado na sessão anterior, assim, a resina não aderiu perfeitamente aos dentes, resultando no deslocamento da contenção em 2 dentes, por isto, foi efetuado uma nova contenção semi-rígida (Figura 3 B).

Figura 3 - A: Radiografia de acompanhamento. B: Nova contenção confeccionada.

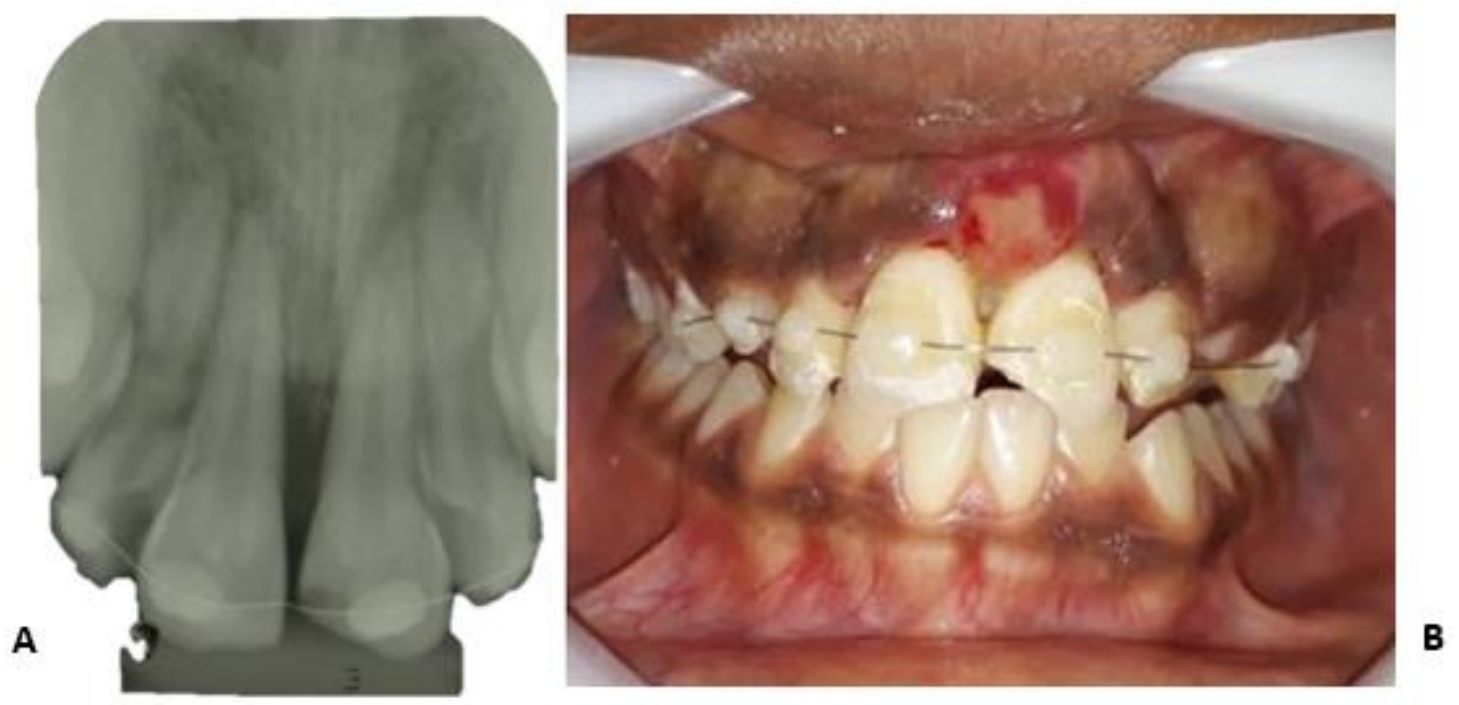

Fonte: Freitas ALS, et al., 2019.

Na terceira sessão, após 15 dias, retirou-se a conteção semi-rigida, foram realizados exames clínicos e radiográfico dos dentes afetados pelo trauma. Os dentes 11 e 21 apresentaram-se assintomáticos, ambos tiveram como resultadonegativo ao teste de vitalidade pulpar, e ambos apresentaram mobilidade dentária 
grau 1. Os dentes 11 e 21 foram diagnósticados com necrose pulpar, e otratamento proposto foi necropulpectomia. Realizou-se o acesso em ambos os dentes. Houve o planejamento do dente 12.

$\mathrm{Na}$ quarta consulta, após 8 dias, foi realizada necropulpectomia com preparo químico-mecânico (PQM) completo no elemento 11, a medicação intracanal selecionada foi pasta callen com paramonoclorofenol canforado (PMCC), e selamento provisório coltosol.

Na quinta sessão, após 13 dias, foi realizado a remoção do selamento provisorio do elemento 21 , seguido da remoção da medicação intracanal (MIC), PQM incompleto e inserido a medicação intracanal tricresolformalina, seguido do selamento provisório com coltosol.

Na sexta sessão, após 7 dias, foi realizado a remoção do provisório do dente 21, remoção da MIC, seguido do PQM completo, e inserido a medicação intracanal pasta callen com PMCC, e após, o selamento provisório coltosol no dente 21.

Na sétima sessão, após 15 dias, notou-se ainda uma reabsorção radicular dos dentes 11 e 21 (Figura 4). Então optou-se pela realização da troca de medicação, e irrigação com hipoclorito de sódio, e inserido a pasta callen com (PMCC) do dente 11.

Figura 4 - Reabsorção na região apical dos elementos 11 e 21.

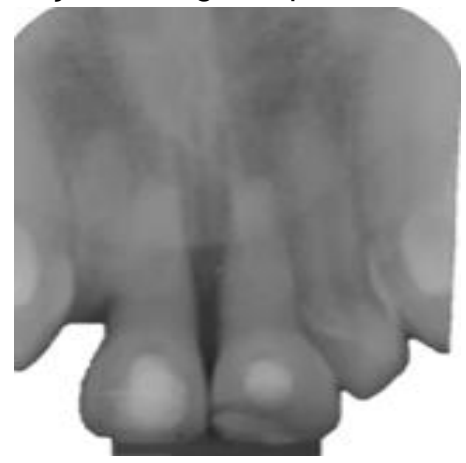

Fonte: Freitas ALS, et al., 2019.

Na oitava sessão, após 8 dias, foirealizado a troca de medicação, e irrigação com hipoclorito de sódio, e inserido a pasta callen com PMCC do dente 21. Na nona sessão, após 8 dias, foi feito o sepultamento da raiz do dente 12, conforme o planejado, para manutenção de espaço e futura inserção de um implante.

Realizou-se a anestesia do nervo alveolar superior anterior, para a retirada da coroa fraturada, após a remoção a mesma foi imergida em soro fisiológico, e realizado os desgastes das arestas para se tornar provisório (Figura 5 A), seguido de uma sutura simples no alveólo com fio de nylon (Figura 5B) e logo após o reposicionamento da coroa (Figura $\mathbf{5}$ C), fixando-a com resina composta na palatina dos dentes adjacentes.

Figura 5 - A: Remoção das arestas para a utilização do mesmo como provisório. B: Realização da sutura simples com fio de nylon 3.0. C: Reposicionamento da coroa fraturada.

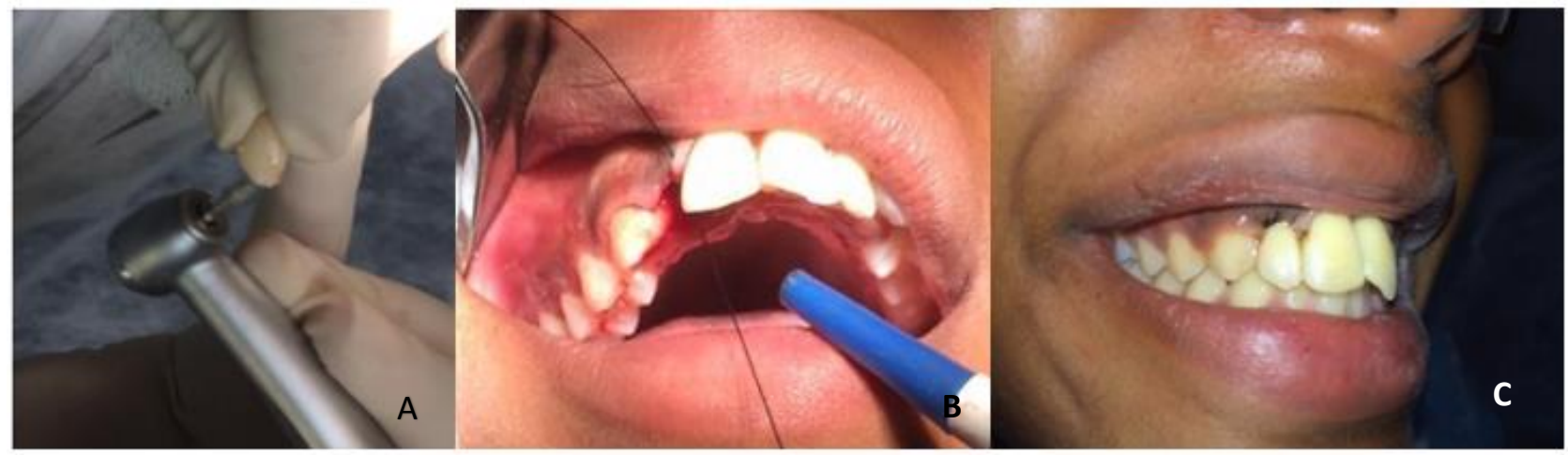

Fonte: Freitas ALS, et al., 2019. 
Na décima sessão, após 3 meses do trauma, os dentes apresentavam sem mobilidade, a reabsorção radicular dos elementos regrediram, assim, foi realizado a obturação dos mesmos com cones de guta percha e cimento endodôntico endofill, logo após o selamento provisório com coltosol. Na décima primeira sessão, após 8 dias, ambos os dentes, 11 e 21, foram restaurados com resina composta, na cor A2 (Figura 6).

Figura 6 - Elementos dentais 11 e 21 com restauração de resina composta A2.

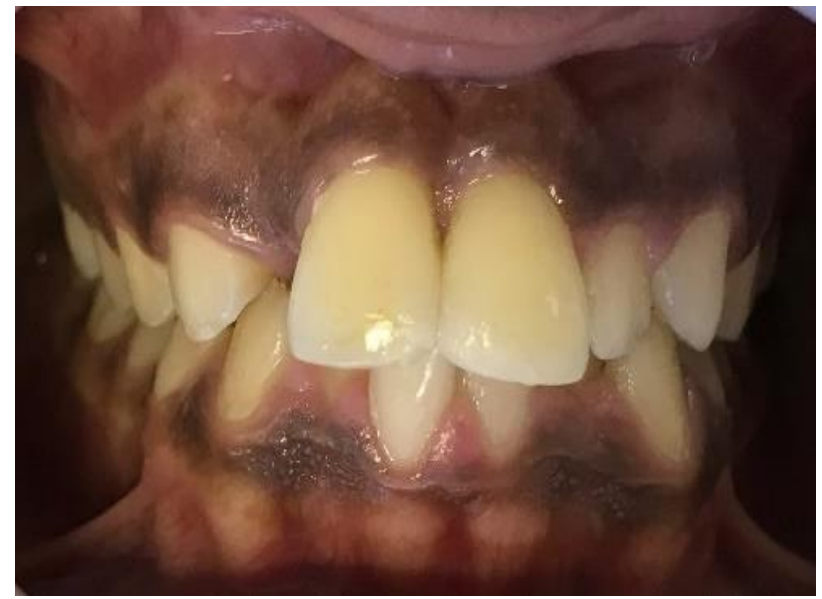

Fonte: Freitas ALS, et al., 2019.

\section{DISCUSSÃO}

As lesões envolvendo elementos dentais e os tecidos periodontais de suporte podem ser classificadas de diversas maneiras a depender da avaliação de cada caso individualmente. Subluxação, concussão, luxação lateral e extrusiva, avulsão e intrusão são como podem ser mencionadas (ARAÚJO AG, 2017). O paciente mencionado no caso retrata um caso de intrusão dentária.

É comum a prevalência de traumas dentários em indivíduos do sexo masculino, devido a uma série de fatores associados a etiologia, como exemplo as quedas, brigas e lutas, acidentes automobilísticos e violência, além dos fatores anatômicos que favorecem os episódios traumáticos (SANTOS JR, et al., 2018).

Um estudo epidemiológico de intrusão traumática de dentes permanentes, realizado por Andreasen JO, et al. (2006), concluiu que a maioria dos casos foram associados a fratura coronária e acometimento de 1 ou 2 dentes, sendo o incisivo central superior o dente com maior incidência e sequelas de necrose pulpar, anquilose e reabsorção radicular. O paciente no presente caso relatado, compõe as características que a literatura salienta quanto a prevalência do sexo masculino, a etiologia do trauma, os dentes afetados e as possíveis sequelas pós-trauma.

Este tipo de trauma na dentição permanente é um dos mais graves e menos comum (ANDREASEN JO, et al., 2006); (DHARMANI U, et al., 2014), devido as sequelas que se estendem a necrose do tecido pulpar, sendo a mais comumente encontrada no primeiro ano após o traumatismo, anquilose, reabsorção radicular e risco de perda do elemento dental (SANTOS RS, et al., 2018).

As opções de tratamento variam levando em consideração o grau de intrusão, onde em casos em que haja uma re-erupção, seja necessário intervir através de tratamentos alternativos, como tração ortodôntica do elemento dental ou reposicionamento cirúrgico, sendo essas opções ligadas respectivamente ao grau do trauma de intrusão (LEMOS IGS, 2018).

A intrusão apresenta um prognóstico duvidoso em relação aos elementos dentais com rizogênese completa, havendo maior chance de re-erupção espontânea em dentes ainda em desenvolvimento e maior chance de ação ortodôntica ou cirúrgica imediata em dentes com desenvolvimento completo.

Cabe ao profissional fazer uma anamnese criteriosa e colher informações subjetivas e clínico-radiográficas para poder concluir um correto diagnóstico e realizar um bom plano de tratamento, o qual deve repercutir de maneira positiva no prognóstico e influenciar no sucesso do tratamento (TRUCCOLO GB, 2018). 
No caso apresentado, a conduta escolhida foi realizar o reposicionamento cirúrgico imediato, pelo grau de intrusão diagnosticado como severo. Segundo Soares I \& Goldberg R, (2011), o reposicionamento cirúrgico é indicado quando a intrusão é caracterizada como grave e o trauma atingiu o osso alveolar.

Oliveira FAM, et al. (2004), relata que um trauma dento-alveolar pode atingir diversas estruturas e que o dano causado por ele irá conduzir o manejo terapêutico, salientando que, quando há casos de fratura coronorradicular, é indicado fazer o uso de contenção, terapia endodôntica, e, dependendo do local e extensão da fratura, a extração da porção coronária.

No presente caso clínico, o dente 12 foi comprometido com fratura coronorradicular, foi realizado a contenção do elemento dental, mas pela extensão da fratura, foi optado posteriormente pela extração coronária e sepultamento da raiz, ficando a critério do paciente e profissional, futuramente, reavaliar as condições para reabilitação de implante.

Casos de intrusão grave requerem uma imobilização fisiológica com duração entre 7 e 15 dias, sendo esse tempo tendendo a ser proporcional ao tempo de cicatrização (TRUCCOLO GB, 2018). O paciente no presente caso apresentado, utilizou contenção semi-rígida por 15 dias, onde os dentes afetados, apresentaram com mobilidade grau I após remoção da contenção. Segundo Oliveira FAM, et al. (2004), a contenção deve favorecer a cicatrização periodontal e reduzir a reabsorção radicular externa.

Devido ao alto risco de complicações pós-acidente, a preservação do trauma de intrusão em dentes permanentes tem grande importância e deve ser de longo prazo.

Os danos causados nas estruturas acometidas no trauma podem resultar em alguns tipos de reabsorção radicular, incluindo a reabsorção inflamatória externa, sendo essa uma das sequelas do caso clínico apresentado (TAVARES AS, 2017).

Uma intervenção endodôntica imediatamente após o trauma deve ser priorizada, ou o mais rápido possível, a fim de prevenir ou retardar a possibilidade do ser desenvolvida uma reabsorção inflamatória, considerando que, independente do grau de intrusão, dentes permanentes maduros (com ápice fechado rizogênese completa) têm a sua polpa necrosada, havendo a indicação para o tratamento endodôntico (GHAFOOR R, 2013).

No caso clínico apresentado, o paciente apresentou necrose pulpar e reabsorção inflámatoria externa, foi iniciado o tratamento endodôntico a fim de paralisar a reabsorção e minimizar os danos. Chaushu S, et al. (2004) e Lemos IGS (2018) expõem que ocorre reabsorção inflamatoria nos casos de necrose pulpar onde o tratamento endodôntico não é realizado rapidamente.

A medicação intra-canal utilizada em várias sessões no tratamento endodôntico do presente caso relatado - hidróxido de cálcio -, segundo Santos JS (2017), é a medicação de primeira escolha para casos com reabsorção inflamatória externa, considerando que medicação a base de hidróxido de cálcio auxilia a interromper a reabsorção e ainda realiza reparação óssea.

Santos JS (2017), indica obturação definitiva no período de 6 a 12 meses se não houver processo de reabsorção ativa. No presente caso clínico, o tratamento endodôntico foi concluído após ser diagnosticado a inatividade de reabsorção.Lemos IGS (2018) aponta que os traumas de intrusão têm como consequência as reabsorções, porém se houverem diagnóstico precoce e tratamento adequado, é possível paralisar a reabsorção.

É possível avaliar o nível de intrusão dentária de acordo com a quantidade de exposição coronária após o trauma. Pode-se agrupar em três categorias, classe I para os elementos dentais com mais de $50 \%$ da coroa visível, classe II para os que possuem menos de $50 \%$ da coroa visível e classe III para os que não possuem a coroa aparente. É comum também as classificar em leve, moderada e severa (LEMOS IGS, 2018), sendo o trauma dental exposto neste trabalho classificado como severo.

Segundo a literatura, as sequelas que envolvem o caso clínico apresentado, necrose pulpar e reabsorção inflamatória externa, levam em consideração o fato da intrusão ter sido severa ( $>6 \mathrm{~mm}$ ) e os dentes afetados serem permanentes e desenvolvidos (ANDREASEN JO, et al., 2006).

Pode-se observar também que, o manejo terapêutico foi decisivo na permanência dos dentes intruidos (11 e 21), pois resultou na reparaçao tecidual e paralização da reabsorção. 


\section{CONSIDERAÇÕES FINAIS}

Sabe-se que os traumatismos dentários necessitam de uma atenção imediata devido a tratamentos meticulosos, levando em consideração sua complexidade nas inúmeras situações em que aparecem. É fundamental que toda a história do trauma seja colhida, levando-se em consideração o tempo decorrido, o grau de intrusão, o estágio de desenvolvimento radicular e o acometimento das estruturas de suporte, a fim de objetivar a melhor modalidade terapêutica, resultando em um bom prognóstico. A intrusão severa apresenta um prognóstico duvidoso, agravado pelas possíveis sequelas como o aparecimento de reabsorções, especialmente em casos de rizogênese completa. No presente caso, o atendimento imediato foi realizado de forma correta, e devido à rizogenese completa, apresentou necrose pulpar nos dentes intruídos, realizando-se a intervenção endodôntica, a fim de que o tratamento fosse eficaz para a resolução do caso com êxito.

\section{REFERÊNCIAS}

1. AMARAL RPR. Traumatismo dentário em dentes permanentes: um estudo retrospectivo de pacientes atendidos no Hospital Universitário de Brasília (HUB) durante 5 anos. Trabalho de Conclusão de Curso (Odontologia) - Faculdade de Ciências da Saúde da Universidade de Brasília, Brasília, 2017; 50p.

2. ANDREASEN JO, et al. Traumatic intrusion of permanent teeth. Part 1. An epidemiological study of 216 intruded permanent teeth. Dental traumatology, 2006; 22(2): 83-89.

3. ARAÚJO AG. Tratamento de dentes necrosados pós trauma. Trabalho de Conclusão de Curso (Odontologia) - União Metropolitana de Educação e Cultura, Lauro de Freitas, 2017; 27p.

4. BROWN CJ. The management of traumatically intruded permanent incisors in children. Dental Update Publication, 2002; 29(1): 38-44.

5. CHAUSHU S, et al. Emergency orthodontic treatment after the traumatic intrusive luxation of maxillary incisors. American Journal of Orthodontics and Dentofacial Orthopedics, 2004; 126: 162-172.

6. COSTA V, et al. Primary Incisor Intruded Through the Nasal Cavity: a Case Report, General Dentistry, 2016; 25(3): 64-67.

7. DHARMANI U. et al. Management of a rare combination of avulsion and intrusive luxation: a case report. Journal of conservative dentistry and Endodontics, 2014; 17(6): 587-589.

8. FINUCANE D, KINIRONS M. External inflammatory and replacement resorption of luxated, and avulsed replanted permanent incisors: a review and case presentation. Dental Traumatology, 2003; 19(3): 170-174.

9. GHAFOOR R. Conservative management of progressive external inflammatory root resorption after traumatic tooth intrusion. Journal of conservative dentistry, 2013; 16(3): 265-268.

10. GRANVILLE-GARCIA AF, et al. Conduta terapêutica dos cirurgiões-dentistas em relação aos traumatismos dentários. Arquivos de Ciênias da Saúde Unipar, 2008; 12(3): 239-247.

11. JACOBS SG. The treatment of traumatized permanent anterior teeth: case report \& literature review. Management of intruded incisors. Australian orthodontic journal, 1995; 13(4): 213-218.

12. LEMOS IGS. Intrusão e extrusão traumática dentária. Dissertação (Mestrado em Medicina Dentária). Universidade Fernando Pessoa (Faculdade de Ciências da Saúde), Porto, 2018; 30p.

13. MARCENES W. Epidemiology of traumatic injuries to the permanent incisors of a 9-12-year-old schoolchildren in Damascus, Syria. Endodontics \& dental traumatology, 1999; 15(3): 117-123.

14. OLIVEIRA FAM, et al. Traumatismo dentoalveolar: revisão de literatura. Revista de Cirurgia e Traumatologia BucoMaxilo-Facial, 2004; 4(1): 15-21.

15. RAI P, et al. A Multidisciplinary Approach to the Management of Traumatic Intrusion in Immature Permanent Teeth, British Medical Journal, 2016; 1-5.

16. SANABE ME, et al. Urgências em traumatismos dentários: classificação, características e procedimentos. Revista Paulista de Pediatria, 2009; 27(4): 447-451.

17. SANTOS JS. Terapêutica endodôntica do sistema de canais radiculares em dentes com rizogênese incompleta: revisão de literatura. Trabalho de Conclusão de Curso (Odontologia) - Centro Universitário São Lucas, Porto Velho, 2017; 25p.

18. SANTOS RS, et al. Traumatismos dentários: conhecimento dos cirurgiões-dentistas da atenção básica à saúde. Rev. Família, Ciclos de Vida e Saúde no Contexto Social, 2018; 6(2): 174-180.

19. SOARES I, GOLDBERG F. Endodontia: técnica e fundamentos. 1. ed. Porto Alegre: Artes Médicas, 2011; 524p.

20. SRIVASTAVA A. et al. How do I manage a patient with intrusion of a permanent incisor? Journal of the Canadian Dental Association, 2014; 1(50): 80.

21. TAVARES AS, et al. Considerações clínicas para o tratamento de dentes avulsionado. Trabalho de Conclusão de Curso (Odontologia) - Universidade Tiradentes, Aracaju, 2017; 37p.

22. TRONSTAD L. Root resorption - etiology, terminology and clinical manifestations. Endododontics and Dental Traumatology, London, 1988; 4(6): 241-52.

23. TRUCCOLO GB. Concussão, subluxação, extrusão, luxação lateral, intrusão e avulsão: uma sugestão de procedimento operacional padrão para a Universidade de Santa Cruz do Sul (UNISC). Trabalho de Conclusão de Curso (Odontologia) - Universidade de Santa Cruz do Sul, Santa Cruz do Sul, 2018; 40p. 